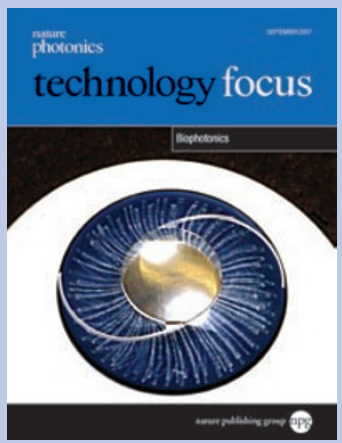

Cover image

Two-photon-absorption processes get an eye for applications.

Industry Perspective p509

EDITOR: OLIVER GRAYDON

ASSOCIATE EDITORS: AMBER JENKINS, DAVID GEVAUX, RACHEL PEI CHIN WON

PRODUCTION EDITORS: SIMON GERRARD, CHRIS GILLOCH

COPY EDITOR: ANNA DEMMING

ART EDITOR: KAREN MOORE

\title{
Living light
}

D

D iophotonics, the topic of this month's Technology Focus, is arguably a sector with the greatest growth potential in future years. With a continual demand for more sophisticated medical-diagnostic and treatment equipment, biophotonics has the potential to meet these needs by harnessing the unique properties of light and putting them to use.

Although biophotonics is often considered to be a contemporary term and its boundaries of coverage are somewhat vague, its origins can arguably be traced back to the adoption of microscopy for biological specimens. Microscopy has clearly come a long way and still plays a vital role in biology, with the development of fluorescent, nonlinear and confocal techniques being good examples, but photonics has a lot more to offer besides. Perhaps the biggest change over the years has been from using light purely as a tool for imaging to realizing its potential as a means for treatment.

Today cells can be manipulated, sorted, operated on and selectively killed by optical techniques, and on a larger scale lasers can cut soft tissue and bone, remove hair or skin defects, or even ablate teeth, for example.

One of the areas where photonics has already had an important impact is in ophthalmology where UV lasers are now routinely used in laser eye surgery, and optical coherence tomography can scan the retina for diseases, such as macular degeneration or glaucoma.

As outlined in our Industry Perspective article on page 509, another future application in ophthalmology could be helping cataract patients after surgery. Here, nonlinear optics could be combined with chemistry to bring two important benefits. The first is to tune the strength of an implanted polymer lens and thus optimize vision by locally adjusting the lens's refractive index. The second is to trigger the release of a cell-killing chemical to prevent the unwanted growth of cells over the artificial lens, which obscures vision. It is innovations like these that show the bright future that photonics has in medicine, and in helping us all maintain good health.
MARKET ANALYSIS

505 In good health Amber Jenkins

\section{RESEARCH HIGHLIGHTS}

507

Towards three-dimensional endoscopy, a multiwavelength bio-wire, and more

\section{INDUSTRY PERSPECTIVE} 509 Ophthalmology: Two-photon treatment

Jens Träger, Hee-Cheol Kim and Norbert Hampp

\section{BUSINESS NEWS}

512

Zecotek plans expansion, Harvard tests cancerimaging prototype, and more

PRODUCT HIGHLIGHTS 513 Deep-tissue scanner, a deformable mirror for eye imaging, and more

\section{INTERVIEW}

The endoscope of the future Interview with Kazunari Nakamura

\section{nature photonics}

